\title{
Improvement of Anthocyanin Encapsulation Efficiency into Yeast Cell by Plasmolysis, Ethanol, and Anthocyanin Concentration Using Response Surface Methodology
}

\author{
Lieu My Dong ${ }^{1 *}$, Hoang Thi Thuy Hang ${ }^{1}$, Nguyen Huyen Nguyet Tran ${ }^{1}$, and Dang Thi Kim Thuy ${ }^{2}$ \\ ${ }^{1}$ Faculty of Food Science and Technology, Ho Chi Minh City University of Food Industry, 140 Le Trong Tan, Tay Thanh Ward, Tan Phu District, \\ Ho Chi Minh City Vietnam \\ ${ }^{2}$ Department of Plain Cell Technology, Institute of Tropical Biology, 9/621 Ha Noi highway, Ho Chi Minh City, Vietnam
}

Received: December 14, 2019 / Revised: February 27, 2020 / Accepted: March 9, 2020

\begin{abstract}
Anthocyanins are antioxidant compounds susceptible to environmental factors. Anthocyanin encapsulation into yeast cells is a viable solution to overcome this problem. In this study, the optimal factors for anthocyanin encapsulation were investigated, including anthocyanin concentration, plasmolysis contraction agent, and ethanol concentration, and response surface methodology was evaluated, for the first time. Anthocyanin from Hibiscus sabdariffa L. flowers was encapsulated into Saccharomyces cerevisiae using plasmolysis contraction agent (B: $3 \%-20 \%$ w/v), ethanol concentration (C: $3 \%-20 \% \mathrm{v} / \mathrm{v})$, and anthocyanin concentration (A: $0.15-0.45 \mathrm{~g} / \mathrm{ml}$ ). The encapsulation yield and anthocyanin loss rate were determined using a spectrometer $(520 \mathrm{~nm})$, and color stability evaluation of the capsules was performed at $80^{\circ} \mathrm{C}$ for $30 \mathrm{~min}$. The results of the study showed that these factors have a significant impact on the encapsulation of anthocyanin, in which ethanol agents have the highest encapsulation yield compared to other factors in the study. Statistical analysis shows that the independent variables $(A, B, C)$, their squares $\left(A^{2}, B^{2}, C^{2}\right)$, and the interaction between $B$ and $C$ have a significant effect on the encapsulation yield. The optimized factors were anthocyanin, $0.25 \mathrm{~g} / \mathrm{ml}$; $\mathrm{NaCl}, 9.5 \%$ (w/v); and ethanol, $11 \%(\mathrm{v} / \mathrm{v})$ with an encapsulation yield of $36.56 \% \pm 0.55 \%$ and anthocyanin loss rate of $15.15 \% \pm 0.98 \%$; This is consistent with the expected encapsulation yield of $35.46 \%$ and loss rate of $13.2 \%$.
\end{abstract}

Keywords: Anthocyanin, encapsulation, ethanol, plasmolysis, Saccharomyces cerevisiae, response surface methodology

\section{Introduction}

Currently, the biological function of anthocyanins such as antioxidant capacity, atherosclerosis prevention, and anticancer activity has been shown to be beneficial in treating diseases [1]. Besides, the replacement of natural food colors is receiving a lot of attention due to

\section{*Corresponding author}

Tel: +84-98996-1848

E-mail: lieudong289@gmail.com

๑) 2020, The Korean Society for Microbiology and Biotechnology the health benefits they bring [2]. However, anthocyanin is easily degraded by many factors such as $\mathrm{pH}$, temperature, light, oxygen, etc. [3]. This motivates studies to find methods to protect bioactive compounds from food, in which encapsulation is considered one of the most effective solutions. The main aim of these microcapsules is to protect sensitive compounds from adverse conditions such as light, moisture, oxygen, etc. [4]. Therefore, there have been many studies suggesting encapsulation methods such as using spray drying and freeze-drying methods $[5,6]$. However, spray drying controls difficult, heteroge- 
neous particle sizes, capsules are easily dissolved in water [5]. Moreover, the process of making products from the spray drying method can affect natural color compounds, leading to the need to search for encapsulation methods more effectively. Recently, there has been considerable interest in the use of encapsulation yeast cells. Because the yeast structure with their presence in human nutrition makes them attractive and a new means of encapsulation for the food industry [7]. Previous studies have shown that yeast cells are used to encapsulate bioactive compounds such as essential oil encapsulated [8], limonene flavor [9], fish oil [4], or enzymes [10]. In the study of Bishop et al. (1998), sodium azide was used to inactivate the cell, allowing passive diffusion to incorporate the compound into the cell. Besides, the extraction of water-soluble components (proteins, saccharides, enzymes, amino acids, nucleic acids) from the cell outside may increase intracellular space [11], leading to increase encapsulation performance. To date, the plasmolyzed using sodium chloride to treat yeast cell inactivation before successful encapsulation is reported in previous studies [12-14]. Similarly, treatment by ethanol increasing membrane permeability showed a significant enhancement of encapsulated efficiency [3]. Besides, the concentration of bioactive substances can influence the envelopment of these color compounds in yeast cells. However, studies evaluating the interaction of the concentration of color, $\mathrm{NaCl}$, and ethanol on the encapsulation yield of color compounds have not yet been published. Also, high-temperature treatment, a common technique in food processing, affects the bioactive compounds of anthocyanin. Therefore, evaluating the heat resistance of anthocyanin after the microencapsulation process is necessary. Response surface methodology (RSM) is a popular optimization method commonly used to find out the correlation as well as the optimal values of impact factors that have many works based on application RSM in chemical and biochemical processes [15]. It is necessary to improve the performance of systems and increase the productivity of processes without increasing costs [16]. The main advantage of RSM is to reduce the number of tests needed to evaluate many parameters, and their interactions are more efficient and easier to arrange and explain these tests than others [17]. In this study, the individual effects of the concentrations of plasmolysis, ethanol, and color on the anthocyanin encapsula- tion yield into yeast cells were investigated. Appropriate jumps are selected and optimized according to the BoxBehnken model to assess the combined effect of factors on encapsulation efficiency and a heat resistance of encapsulated anthocyanin.

\section{Material and Methods}

\section{Plant material}

Hibiscus sabdariffa L. (Fig. 1) from Binh Thuan province, located at $10^{\circ} 56^{\prime} \mathrm{N} 108^{\circ} 6^{\prime} \mathrm{E}$ in the southeast region of Vietnam, was used in this study. Calyces were dried at $45^{\circ} \mathrm{C}$ for $60 \mathrm{~h}$, after removing washed and separated seeds. Dried calyces were crushed and sealed until used. Anthocyanin extraction from calyces was performed according to the description of Nguyen et al. [3] with slight modifications. Ten-gram of sample was diluted in $100 \mathrm{ml}$ of distilled water for $20 \mathrm{~min}$ at room temperature. Collected products was concentrated by evaporating water at $60^{\circ} \mathrm{C}$ and at $650 \mathrm{mmHg}$ pressure with a vacuum rotary device. From the color translation of $0.45 \mathrm{~g} / \mathrm{ml}$, the solution was diluted to $0.15 \mathrm{~g} / \mathrm{ml}$ and $0.3 \mathrm{~g} /$ $\mathrm{ml}$ respectively, and stored at $4^{\circ} \mathrm{C}$.

\section{Microorganisms and culture}

Saccharomyces cerevisiae was obtained from the strain collection of Faculty of Food Science and Technology, Ho Chi Minh City University of Food Industry. The yeast cells were grown in Hansen agar for $24 \mathrm{~h}$ at $30^{\circ} \mathrm{C}$. Then, the biomass was harvested by rinsing plates with $\mathrm{NaCl}$ $0.9 \%(\mathrm{w} / \mathrm{v})$ and centrifuged (5000 rpm) for $10 \mathrm{~min}$. The yeast cells were used in the next encapsulation process.

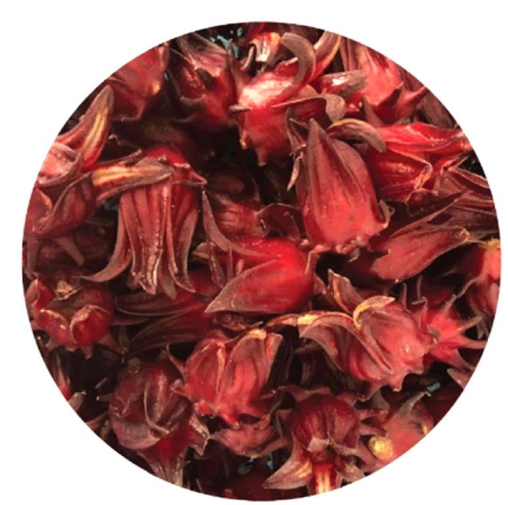

Fig. 1. Hibiscus sabdariffa L. 
The effect of anthocyanin concentration on encapsulation efficiency into S. cerevisiae

Plasmolysis treatment. The biomass of yeast was plasmolyzed with $5 \% \mathrm{NaCl}$, and the solid fraction obtained after centrifugation was mix with anthocyanin $(0.15 ; 0.3$; $0.45 \mathrm{~g} / \mathrm{ml}$ ) in $1 \mathrm{~h}, 120 \mathrm{rpm}$ at $30^{\circ} \mathrm{C}$. Biomass after encapsulated and determined encapsulation yield by measure infrared spectrum.

The effect of $\mathrm{NaCl}$ concentration on encapsulation efficiency into S. cerevisiae. The anthocyanin fixation procedure from yeast cells was carried out according to the description of Paramera et al. (2011) with some changes summarized below [11]: Yeast (0.5 gram fresh) was treated plasmolysis with concentrations of $\mathrm{NaCl}(3 ; 5$; $10 ; 15 ; 20 \%(\mathrm{w} / \mathrm{v})$, incubation $24 \mathrm{~h}, 120 \mathrm{rpm}$ at $30^{\circ} \mathrm{C}$. The biomass obtained after centrifugation mixed with anthocyanin color $(0.3 \mathrm{~g} / \mathrm{ml})$ for $1 \mathrm{~h}, 120 \mathrm{rpm}$ at $30^{\circ} \mathrm{C}$. Biomass was determined encapsulation yield and thermal stability of anthocyanin.

The effect of ethanol concentration on encapsulation efficiency into $\boldsymbol{S}$. cerevisiae. The effect of ethanol on anthocyanin immobilization ability on yeast cells was performed according to the description of Nguyen et al. (2018) with some changes summarized below [3]: yeast biomass (0.5 gram) mixed with anthocyanin color translation $(0.3 \mathrm{~g} / \mathrm{ml})$ in ethanol solution with concentrations of $3 ; 10 ; 20 ; 30 \%(\mathrm{v} / \mathrm{v})$ incubated $1 \mathrm{~h}, 120 \mathrm{rpm}$ at $30^{\circ} \mathrm{C}$. Biomass was determined encapsulation yield and thermal stability of anthocyanin.

Influence of the combined effect of color concentration, plasmolysis, and ethanol contraction on encapsulation efficiency into $S$. cerevisiae

Yeast biomass (0.5 gram) after treatment plasmolysis in different $\mathrm{NaCl}$ concentrations is mixed with anthocyanin color solution for $1 \mathrm{~h}, 120 \mathrm{rpm}$ at $30^{\circ} \mathrm{C}$. Biomass was determined encapsulation yield and thermal stability of anthocyanin.

Yeast biomass (0.5 gram) treated ethanol at different concentrations was mixed with anthocyanin color solution for $1 \mathrm{~h}, 120 \mathrm{rpm}$ at $30^{\circ} \mathrm{C}$. Biomass was determined encapsulation yield and thermal stability of anthocyanin.

Yeast biomass (0.5 gram) after treatment plasmolysis at different $\mathrm{NaCl}$ concentrations was mixed with anthocyanin color solution in ethanol solution at concentrations of $1 \mathrm{~h}, 120 \mathrm{rpm}$ at $30^{\circ} \mathrm{C}$. Biomass was determined encapsulation yield and thermal stability of anthocyanin.

\section{Effect of temperature on the ability of Saccharomyces cer- evisiae to retain anthocyanin color}

Anthocyanin encapsulated yeast cells were incubated in the water bath at $80^{\circ} \mathrm{C}$ for $30 \mathrm{~min}$ and evaluated for the thermal stability of anthocyanin.

\section{Control samples}

The control sample $(+)$ is a sample that did not take any treatment steps. Yeast cells (0.5 gram) after were cultured, which was mixed with anthocyanin fluid $(0.3 \mathrm{~g} /$ $\mathrm{ml}$ ) for $1 \mathrm{~h}, 120 \mathrm{rpm}$ at $30^{\circ} \mathrm{C}$. The biomass was harvested by centrifugation, evaluated for encapsulation yield, and thermal stability of anthocyanin

\section{Optimizing the factors affecting the fixation of encapsula- tion efficiency into $S$. cerevisiae}

The response surface method uses Box-Behnken design to optimize factors: color concentration (A), $\mathrm{NaCl}$ (B), ethanol (C). The experimental design consists of 17 experiments of three variables $(\mathrm{A}, \mathrm{B}, \mathrm{C})$ at three levels $(-1 ; 0 ; 1)$. Independent variables are coded -1 and 1 at low and high levels. The scope of implementation and the value are shown in Table 1. All experiments were performed three times and the average performance was obtained as the dependent variable (Y). The following quadratic polynomial equation is used to study the effect of variables on encapsulation yield and color loss rate:

$$
\begin{aligned}
\mathrm{Y} & =\beta_{0}+\beta_{1} \mathrm{~A}+\beta_{2} \mathrm{~B}+\beta_{3} \mathrm{C}+\beta_{11} \mathrm{~A}^{2}+\beta_{22} \mathrm{~B}^{2} \\
& +\beta_{33} \mathrm{C}^{2}+\beta_{12} \mathrm{AB}+\beta_{13} \mathrm{AC}+\beta_{23} \mathrm{BC}
\end{aligned}
$$

where $\mathrm{Y}$ is the encapsulation yield and color loss rate, $\beta_{0}$ is the constant term; $\beta_{1}, \beta_{2}$, and $\beta_{3}$ are the coefficient of

Table 1. Experimental range, level, and code of independent variables.

\begin{tabular}{cccccc}
\hline \multirow{2}{*}{$\begin{array}{c}\text { Independent } \\
\text { variables }\end{array}$} & \multirow{2}{*}{ Unit } & $\begin{array}{c}\text { Symbol } \\
\text { coded }\end{array}$ & \multicolumn{3}{c}{ Range and levels } \\
\cline { 4 - 6 } & & -1 & 0 & +1 \\
\hline Anthocyanin & $\mathrm{g} / \mathrm{ml}$ & $\mathrm{A}$ & 0.15 & 0.3 & 0.45 \\
$\mathrm{NaCl}$ & $\%$ & $\mathrm{~B}$ & 3 & 11.5 & 20 \\
Ethanol & $\%$ & $\mathrm{C}$ & 3 & 11.5 & 20 \\
\hline
\end{tabular}


linear terms; $\beta_{11}, \beta_{22}$ and $\beta_{33}$ are the coefficient of quadratic terms; and $\beta_{12}, \beta_{13}$ and $\beta_{23}$ are the coefficient of cross-product terms, respectively.

Independent variables are optimized by the desired function criteria available in Design-Expert software (version 7.1.5). The goal is to maximize encapsulation yield and color loss rate while keeping variables in the corresponding test range.

\section{Methods of determining anthocyanin content}

The method of determining the content of anthocyanin is based on the description of Nguyen et al. [3] that used to determine the anthocyanin content by spectrometers (520 nm) calculated by Beer-Lamber formula:

$$
A C=\frac{A b s \times M \times D \times 10^{3}}{\varepsilon \times l}
$$

Abs: Absorbance of the diluted solution $\left(\lambda_{\max }=520 \mathrm{~nm}\right)$.

M: Molecular weight: 465.2 (g.mol 1).

D: Dilution factor.

$\varepsilon$ : (Delphinidin-3-glucosides): 23,700 (L.mole ${ }^{-1} \mathrm{~cm}^{-1}$ )

$\mathrm{l}$ : Length of the optical path in the cuvette $(1 \mathrm{~cm})$

\section{Encapsulation yield}

$\operatorname{EY}(\%)=\frac{Q_{E}}{Q_{T}} \times 100$

$\mathrm{Q}_{\mathrm{E}}$ : was the amount (g) of anthocyanin encapsulated

$\mathrm{Q}_{\mathrm{T}}$ : amount (g) of anthocyanin in the original sample

\section{Statistical analysis}

All data are expressed in a meaningful form \pm standard deviation (SD), at least 3 repetitions for each treatment. The difference between the variables is checked by using the ANOVA test. Design-Expert 7.0 software used for evaluating the effect of factors agents on the anthocyanin encapsulation yield by response surface methods.

\section{Results and Discussion}

\section{Influence of anthocyanin concentration factor, plasmoly- sis and ethanol contraction on encapsulation efficiency into S. cerevisiae}

Encapsulation yield of anthocyanin into Saccharomyces cerevisiae under the influence of color concentration, $\mathrm{NaCl}$ and ethanol concentration is shown in Fig. 2. The results show that in samples containing untreated yeast cells, the color was recorded at $10 \%$, the lowest $(p<0.05)$ compared to samples containing treated yeast cells (Fig. 2). In the investigation of the effect of anthocyanin concentration on encapsulation yield, with concentration of $0.15 ; 0.3$ and $0.45 \mathrm{~g} / \mathrm{ml}$ increase encapsulation yield EY of $11.22 \pm 0.28 \% ; 15.05 \pm 1.27 \%$, and $18.21 \pm 0.35 \%$ (Fig. $2 \mathrm{~A})$. The results obtained from the treatment of plasmolysis by contraction $\mathrm{NaCl}$ showed that the concentration of $\mathrm{NaCl}$ affected $\mathrm{EY}$ encapsulation yield increased from $11.78 \%$ to $23.65 \%$ when increasing the corresponding $\mathrm{NaCl}$ concentration from $3 \%$ to $15 \%$, twice higher than untreated yeast samples (EY 10\%). However, when the $\mathrm{NaCl}$ concentration was increased to $20 \%$, the encapsulation yield decreased to $17.75 \pm 1.08 \%$ (Fig. 2B). The impact of ethanol showed that when the ethanol concentration increased from 3 to $30 \%(\mathrm{w} / \mathrm{v})$, the anthocyanin encapsulation yield from $12.86 \pm 0.95 \%$ to $26.11 \pm 1.12 \%$. However, color loss due to a high temperature significantly increased $(p<0.05)$ when heating at the sample treated by ethanol $30 \%$ compared to the remaining samples in the survey (Fig. 2C).
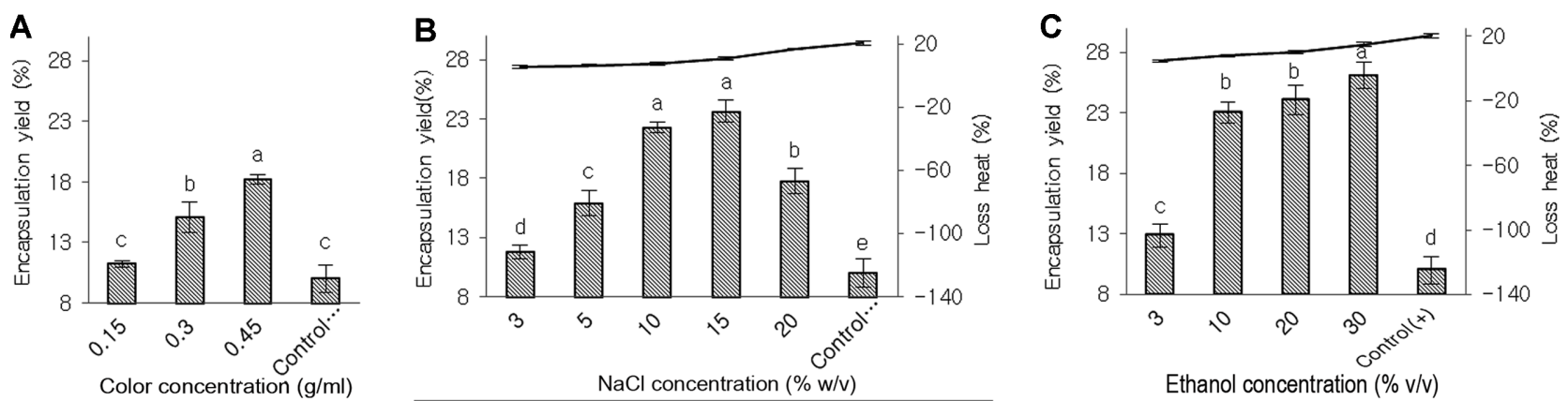

Fig. 2. Encapsulation yield and color loss rate under the influence of color concentration (A), $\mathrm{NaCl}$ concentration (B), ethanol concentration (C). abcde is the average value of the column and the difference of characters is statistically significant $(p<0.05)$. 
The concentration of encapsulation-compounds has significant effects on encapsulation yield. A high concentration of encapsulation-compound increases encapsulation yield (Fig. 2A). However, the high concentration of encapsulation compounds is also a factor in the reduction of cell loading, leading to do not increase in encapsulation yield \%EY [11]. High anthocyanin concentrations $(0.45 \mathrm{~g} / \mathrm{ml})$ increase the viscosity of color fluids. This makes it possible to increase the color to $0.45 \mathrm{~g} / \mathrm{ml}$ by 1.5 times $0.3 \mathrm{~g} / \mathrm{ml}$, but the encapsulation yield does not increase accordingly (Fig. 2A).

The effect of plasmolysis on the encapsulation yield of encapsulation compounds into yeast cells has been published in previous studies. Plasmolysis is the phenomenon of draining water out of cells, in which cells are incubated in high saline or sugar solution [18]. Plasmolysis has the ability to increase intracellular space or rate of packaging and reduce protein, nucleic acid in cellular components [7]. Paramera et al. (2011) suggested that the process of plasmolysis in curcumin encapsulated is not effective [11]. However, the results from this study (Fig. 2B) concur with Shi et al. (2007) that the effect of treating plasmolysis with $\mathrm{NaCl} 5 \%$ concentration (w/v) for chlorogenic encapsulation yield doubled compared to the control sample [13]. Similarly, encapsulated drugs containing biological compound treated $\mathrm{NaCl} 5 \%$ for $24 \mathrm{~h}$ helps increase encapsulation yield by eliminating intracellular components of yeast cells and higher encapsulation yield than spray drying, freeze-drying [19]. Results from this study showed that $\mathrm{NaCl} 10 \%$ concentration for anthocyanin encapsulation yield was significantly higher $(p<0.05)$ than $5 \%$ concentration (Fig. $2 \mathrm{~B}$ ). This shows that the encapsulated of compounds into yeast cells depends on the type of compound encapsulated and the concentration of the plasmolysis agent.

Besides $\mathrm{NaCl}$, ethanol has also been shown to play a role in the physicochemical and physiological functions of widely studied cell membranes [20]. Under the action of ethanol, the double lipid layer undergoes a phase transition that significantly reduces its thickness [3]. Thus, ethanol alters the area and thickness of the lipid layer resulting in changes in the mechanical properties of permeability and diffusion of cell membranes [21]. In addition, ethanol forms a layer on the membrane, compounds that can be used to increase fluidity. These effects make anthocyanin encapsulated into yeast cells more effective than not treated by ethanol (Fig. 2C). However, soluble molecules in membranes do not always increase but can reduce fluidity (due to increased viscosity) [18]. In previous studies, a high concentration of ethanol $(50 \% \mathrm{v} / \mathrm{v})$ caused curcumin encapsulation yield decreased double from $33.8 \%$ to $16.6 \%$ [1], the encapsulated resveratrol only achieved $4.52 \%$ efficiency [14]. The results of this study show that increasing the concentration of ethanol increases encapsulation yield (Fig. 2C). However, when the concentration increases to $30 \%$, the encapsulation yield increases but when affected by high temperatures, the color molecules are easily dispersed leading to a large color loss rate compared to the remaining concentrations (Fig. 2C). This can be explained by the large concentration of ethanol which completely removes the permeability of cell membranes. The results from the study show that the factors in the survey have a significant impact on the anthocyanin encapsulation yield of yeast cells (Fig. 2). As a result, finding the correlation between factors is necessary to determine the interactions for the highest encapsulation yield with the lowest color loss rate.

Table 2. Box Behnken design for independent variables encapsulation yield, and color loss rate.

\begin{tabular}{ccccccc}
\hline Std & Run & $\begin{array}{c}\text { Color } \\
(\mathrm{g} / \mathrm{ml})\end{array}$ & $\begin{array}{c}\mathrm{NaCl} \\
(\%)\end{array}$ & $\begin{array}{c}\text { Ethanol } \\
(\%)\end{array}$ & $\begin{array}{c}\mathrm{EY}(\%) \\
\text { loss }(\%)\end{array}$ & $\begin{array}{c}\text { Color } \\
\text { lo }\end{array}$ \\
\hline 1 & 14 & 0.15 & 3 & 11.5 & 24.45 & 10.11 \\
3 & 11 & 0.15 & 20 & 11.5 & 28.15 & 15.45 \\
5 & 7 & 0.15 & 11.5 & 3 & 21.15 & 11.65 \\
7 & 13 & 0.15 & 11.5 & 20 & 27.98 & 13.88 \\
9 & 12 & 0.3 & 3 & 3 & 18.85 & 7.5 \\
10 & 1 & 0.3 & 20 & 3 & 28.55 & 16.22 \\
11 & 2 & 0.3 & 3 & 20 & 26.65 & 15 \\
12 & 16 & 0.3 & 20 & 20 & 25.34 & 25.05 \\
13 & 6 & 0.3 & 11.5 & 11.5 & 38.75 & 13.88 \\
14 & 15 & 0.3 & 11.5 & 11.5 & 37.45 & 13.21 \\
15 & 5 & 0.3 & 11.5 & 11.5 & 37.45 & 14.52 \\
16 & 4 & 0.3 & 11.5 & 11.5 & 35.5 & 12 \\
17 & 10 & 0.3 & 11.5 & 11.5 & 36.99 & 12.78 \\
2 & 3 & 0.45 & 3 & 11.5 & 27.87 & 15.41 \\
4 & 8 & 0.45 & 20 & 11.5 & 29.68 & 20.45 \\
6 & 9 & 0.45 & 11.5 & 3 & 29.11 & 17.68 \\
8 & 17 & 0.45 & 11.5 & 20 & 31.14 & 19.88 \\
\hline
\end{tabular}


Optimizing the factors affecting the encapsulation efficiency into S. cerevisiae

Table 2 shows the process variables and test data 17 runs containing 5 iterations at the central point. By applying the analysis of test data, the model for the variable is represented by the following quadratic equation in the form of encoded values:

$$
\begin{aligned}
\mathrm{Y}_{1} & =37.23+2.01 \mathrm{~A}+1.74 \mathrm{~B}+1.68 \mathrm{C}-0.47 \mathrm{AB} \\
& -1.2 \mathrm{AC}-2.75 \mathrm{BC}-3.6 \mathrm{~A}^{2}-6.09 \mathrm{~B}^{2}-6.29 \mathrm{C}^{2} \\
\mathrm{Y}_{2} & =14.98+2.79 \mathrm{~A}+3.64 \mathrm{~B}+2.6 \mathrm{C}
\end{aligned}
$$

In which, $\mathrm{Y}_{1}$ is the encapsulation yield, $\mathrm{Y}_{2}$ is the color loss rate, the values $\mathrm{A}, \mathrm{B}, \mathrm{C}$ are color, $\mathrm{NaCl}$ and ethanol respectively.

ANOVA variance analysis for the model is presented in Table 3. For the objective function $\mathrm{Y}_{1}$, the coefficient of determination $\left(\mathrm{R}^{2}=0.9753\right)$ indicates that $2.47 \%$ of the total variation is not explained by the model. For a good statistical model, the adjusted coefficient of deter- mination $R^{2}$ adj must be close to $R^{2}$. As adjusted Table 3 $\mathrm{R}_{\text {adj }}^{2}$ (0.9436) near $\mathrm{R}^{2}$. Furthermore, $\mathrm{R}_{\text {pred }}^{2}(0.7487)$ matches $\mathrm{R}_{\text {adj }}^{2}$ and confirms this model significantly. Similarly, the objective function Y2 coefficient determines $R_{\text {adj }}^{2}(0.7653)$ close to $R^{2}(0.8093), R_{\text {pred }}^{2}(0.6651)$ in accordance with $\mathrm{R}_{\text {adj }}^{2}$ and confirms this model significantly. The "Lack of fit" $0.2602>0.05$ and $0.0546>0.05$, with no significance compared to pure error and indicates a suitable model to describe the test data. Inconsistent accuracy is a measure of signal/noise ratio, a ratio greater than 4 is desirable. The value of the appropriate accuracy is 17,397 and 13,216 indicates an adequate signal. Therefore, the full prediction model is within the scope of experimental variables. The importance of each coefficient is measured by the $p$-value and the $F$ value is listed in Table 3 . The $\mathrm{p}$-value of the model is less than 0.0001 which indicates that the model is significant and can be used for darkening optimization of variables.

$3 \mathrm{D}$ response surface and $2 \mathrm{D}$ contour plot lines are

\begin{tabular}{|c|c|c|c|c|c|c|c|}
\hline Source & & Sum of Squares & df & Mean Square & F-Value & $\mathrm{p}$-value Prob $>\mathrm{F}$ & \\
\hline \multicolumn{8}{|c|}{ Encapsulation yield (\%EY) } \\
\hline Model & & 534.43 & 9 & 59.38 & 30.72 & $<0.0001$ & significant \\
\hline A-Color & & 32.28 & 1 & 32.28 & 16.70 & 0.0047 & \\
\hline B-Nacl & & 24.15 & 1 & 24.15 & 12.49 & 0.0095 & \\
\hline C-Ethanol & & 22.61 & 1 & 22.61 & 11.70 & 0.0111 & \\
\hline$A B$ & & 0.89 & 1 & 0.89 & 0.46 & 0.5186 & \\
\hline$A C$ & & 5.76 & 1 & 5.76 & 2.98 & 0.1280 & \\
\hline$B C$ & & 30.31 & 1 & 30.31 & 15.68 & 0.0055 & \\
\hline$A^{2}$ & & 54.46 & 1 & 54.46 & 28.17 & 0.0011 & \\
\hline$B^{2}$ & & 156.37 & 1 & 156.37 & 80.89 & $<0.0001$ & \\
\hline$C^{2}$ & & 166.40 & 1 & 166.40 & 86.08 & $<0.0001$ & \\
\hline Residual & & 13.53 & 7 & 1.93 & & & \\
\hline Lack of Fit & & 8.07 & 3 & 2.69 & 1.97 & 0.2602 & not significant \\
\hline \multicolumn{8}{|l|}{ Color loss (\%) } \\
\hline Model & & 222.42 & 3 & 74.14 & 18.4 & $<0.0001$ & significant \\
\hline A-Color & & 62.33 & 1 & 62.33 & 15.4 & 0.0017 & \\
\hline B-Nacl & & 106.22 & 1 & 106.22 & 26.35 & 0.0002 & \\
\hline C-Ethanol & & 53.87 & 1 & 53.87 & 13.37 & 0.0029 & \\
\hline Residual & & 52.39 & 13 & 4.03 & & & \\
\hline Lack of Fit & & 48.60 & 9 & 5.4 & 5.7 & 0.0546 & not significant \\
\hline $\mathrm{Y} 1:=\mathrm{R}^{2}=0.9753$ & $R_{a d j}^{2}=0.9436$ & $\mathrm{R}_{\text {pred }}^{2}=0.7487$ & \multicolumn{5}{|c|}{ Adeq Precision $=17.397$} \\
\hline$Y 2:=R^{2}=0.8093$ & $R_{a d j}^{2}=0.7653$ & $3 R_{\text {pred }}^{2}=0.6651$ & \multicolumn{3}{|c|}{ Adeq Precision $=13.218$} & & \\
\hline
\end{tabular}
graphical representations of the regression equation

Table 3. Analysis of variance for the fitted quadratic model. 
which are useful for adjusting the relationship between independent variables and dependent variables. Different shapes of contour lines indicate whether the interaction between variables is significant. The $3 \mathrm{D}$ response surface and $2 \mathrm{D}$ contour plots created by the model are shown in Fig. 3. In these three variables, when the two variables are described in a three-dimensional surface cell, the third variable is tried set at 0 .

From the above model and from the results of variance analysis in Table 3, it was found that the three factors of color, $\mathrm{NaCl}$ and ethanol have a significant influence on the objective function $\mathrm{Y}_{1}$ as the encapsulation yield $(p<0.05)$. However, different technological factors have a different effect. The results from the model show that the individual factors of color (A), $\mathrm{NaCl}(\mathrm{B})$, ethanol (C) all affect the objective function $\mathrm{Y}_{1}(p<0.05)$, and their square also affects intentionally meaning to the objective function $\mathrm{Y}_{1}(p<0.05)$. Similar to the objective function $\mathrm{Y}_{2}$, three factors color, $\mathrm{NaCl}$ and ethanol have significant effects on the objective function $\mathrm{Y}_{2}$ as color loss rate $(p<0.05)$. Positive values of regression coefficients indicate that the objective function value $\mathrm{Y}_{2}$ is higher when
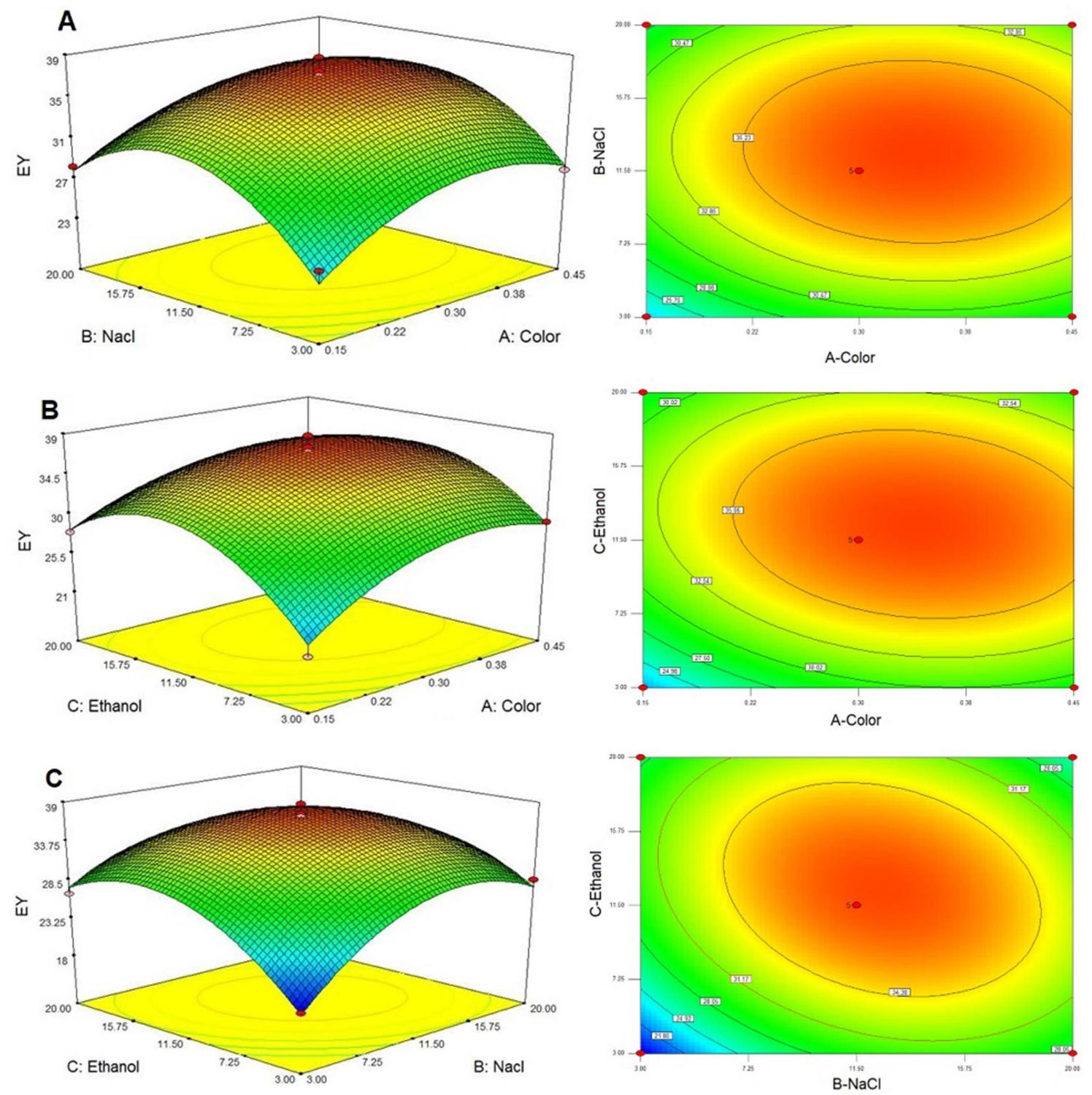

Fig. 3. Response surface and contour plots. (A) the effect of color concentration and $\mathrm{NaCl}$ concentration; (B) the effect of color concentration and ethanol concentration; $(\mathrm{C})$ the effect of $\mathrm{NaCl}$ concentration and ethanol concentration. 
increasing the influencing factors.

As seen in Fig. 3A, the color interaction pairs (A) and $\mathrm{NaCl}$ (B) have no significant effect on the target function $\mathrm{Y}_{1}$. In this case, the color (A) and $\mathrm{NaCl}$ (B) do not have much interaction in accordance with the contour plots in Fig. $3 \mathrm{~A}$ and Table 3 results when the coefficient $A B$ is not significant $(p>0.05 \%)$. Similar to Fig. $3 \mathrm{~B}$ color interactions (A) and ethanol (C) when increasing both $\mathrm{A}$ (color) and C (ethanol), encapsulation yield increases slowly. Ethanol continues to increase to $20 \%$, the encapsulation yield begins to decrease. The concentration of color continues to increase encapsulation yield still increased slightly. Demonstrate the interaction of two negligible variables, consistent with contour plots Fig. $3 \mathrm{~B}$ and Table 3 when the $\mathrm{AC}$ coefficient is not significant ( $p>0.05 \%$ ). In the case of Fig. 3C, both $\mathrm{NaCl}(\mathrm{B})$ and ethanol (C) both affect EY encapsulation yield and have a quadratic effect on encapsulation yield which increases efficiency. Ethanol and $\mathrm{NaCl}$ act on cell membranes to increase permeability to facilitate easy anthocyanin color molecules to spread into yeast cells. The encapsulation yield increases rapidly when ethanol and $\mathrm{NaCl}$ increase, but when $\mathrm{NaCl}$ exceeds $11.5-17 \%$, the encapsulation yield starts to decrease due to the high concentration of $\mathrm{NaCl}$ negatively affecting the cell membrane. This is consistent with the contour's plots Fig. $3 \mathrm{C}$ and Table 3 when the BC coefficient is significant $(p<0.05)$.

Through 3D models and their respective contour plots, the fit of the model equation to predict the optimal response values has been checked by the selected optimal conditions. Results Table 4 shows the optimum color conditions of $0.26 \mathrm{~g} / \mathrm{ml}, \mathrm{NaCl} 9.38 \%$, and ethanol $10.82 \%$. Under such conditions, packaging efficiency was $35.46 \%$, and the color loss rate was $13.20 \%$. However, considering the ability to operate in actual production, the optimal conditions can be modified as follows: anthocyanin concentration $0.25 \mathrm{~g} / \mathrm{ml}, \mathrm{NaCl}$ 9.5\%, ethanol 11\%. Under actual modification conditions, packaging performance reached $36.56 \pm 0.55 \%$ and the color loss rate was

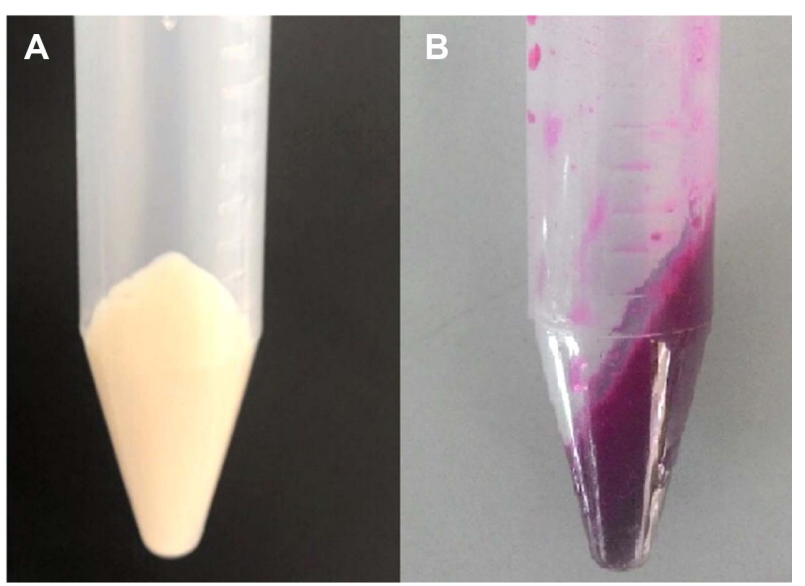

Fig. 4. The biomass of yeast cell before (A) and after (B) encapsulation process.

$15.15 \pm 0.98 \%$ close to the predicted value (Table 4 ). Previous studies have shown that the concentration of color compounds, $\mathrm{NaCl}$, and ethanol significantly affect encapsulation yield in yeast cells (Paramera et al., 2011; Shi et al., 2008; Nguyen et al., 2018). However, studying the correlation as well as the interaction between these factors has not been published. The results from this study indicate the correlation between the factors as well as micro-conditions for the highest encapsulation yield with the lowest color loss rate (Fig. 4, Table 4). Microencapsulation efficiency, as well as heat resistant ability promising application potential of natural color compounds in food which high-temperature requesting such as cookies, etc. Subsequent studies need to assess the application ability in food processing as well as the release of anthocyanin after the encapsulation process.

\section{Conclusion}

Results from the study showed that anthocyanin, $\mathrm{NaCl}$ and ethanol concentrations both significantly affected anthocyanin encapsulation yield into yeast cells. The interaction of anthocyanin concentration and $\mathrm{NaCl}$ con-

Table 4. Optimal conditions, predictive values and tests at optimal conditions.

\begin{tabular}{|c|c|c|c|c|c|}
\hline & $\begin{array}{l}\text { Anthocyanin color } \\
\mathrm{g} / \mathrm{ml}\end{array}$ & $\begin{array}{c}\mathrm{NaCl} \\
\%(\mathrm{w} / \mathrm{v})\end{array}$ & $\begin{array}{l}\text { Ethanol \% } \\
\qquad(\mathrm{v} / \mathrm{v})\end{array}$ & $\begin{array}{l}\text { Encapsulation } \\
\text { yield (\%) }\end{array}$ & $\begin{array}{c}\text { Color loss rate } \\
(\%)\end{array}$ \\
\hline Optimal conditions (predictions) & 0.26 & 9.38 & 10.82 & 35.46 & 13.20 \\
\hline Actual conditions (revised) & 0.25 & 9.5 & 11 & $36.56 \pm 0.55$ & $15.15 \pm 0.98$ \\
\hline
\end{tabular}


centration as well as anthocyanin concentration and ethanol concentration are not significant. On the other hand, the interaction between $\mathrm{NaCl}$ and ethanol was significant and had a positive impact on encapsulation yield. Pretreatment encapsulation as plasmolysis with $\mathrm{NaCl}$ significantly increased encapsulation yield. In addition to combining the effects of ethanol with increased permeability, anthocyanin color molecules easily diffuse into yeast cells. The use of response surface methodology has been shown to be effective in finding concentrations of encapsulating conditions to improve encapsulation yield while keeping color loss rate at a lowest level. The conditions of the impact factors for optimal encapsulation yield and color loss rate were as follows: Color concentration $0.25 \mathrm{~g} / \mathrm{ml}, \mathrm{NaCl} 9.5 \%$, ethanol $11 \%$. Under these conditions, the test encapsulation yield was $36.56 \pm 0.55 \%$ and the color loss rate was $15.15 \pm 0.98 \%$, which is close to the expected value of encapsulation yield of $35.46 \%$ and color loss rate of $13.2 \%$. Moreover, the encapsulation stabilizes color degradation by high temperatures. Yeast cells are capable of promising applications for color compound encapsulation in food products and the application potential in food products that hightemperature requesting.

\section{Conflict of Interest}

The authors have no financial conflicts of interest to declare.

\section{References}

1. Tsai PJ, McIntosh J, Pearce P, Camden B, Jordan BR. 2002. Anthocyanin and antioxidant capacity in Roselle (Hibiscus sabdariffa L.) extract. Food Res. Int. 35: 351-356.

2. Muhamad II, Jusoh YM, Nawi NM, Aziz AA, Padzil AM, Lian HL. 2018. Advanced natural food colorant encapsulation methods: Anthocyanin plant pigment. pp. 495-526. Natural and Artificial Flavoring Agents and Food Dyes.

3. Nguyen TT, Phan-Thi H, Pham-Hoang BN, Ho PT, Tran TTT, Waché Y. 2018. Encapsulation of Hibiscus sabdariffa L. anthocyanins as natural colors in yeast. Food Res. Int. 107: 275-280.

4. Czerniak A, Kubiak P, Białas W, Jankowski T. 2015. Improvement of oxidative stability of menhaden fish oil by microencapsulation within biocapsules formed of yeast cells. J. Food Eng. 167: 2-11.

5. Mahdavi SA, Jafari SM, Ghorbani M, Assadpoor E. 2014. Spraydrying microencapsulation of anthocyanins by natural biopolymers: A review. Dry. Technol. 32: 509-518.

6. Sahat NS, Zaidel DNA, Muhamad I I, Alam MNHZ. 2014. Stability study of water-in-oil emulsion containing anthocyanins from red cabbage. J. Teknol. 69. DOI:10.11113/JT.V69.3163

7. Paramera El, Karathanos VT, Konteles SJ. 2014. Yeast cells and yeast-based materials for microencapsulation. Microencapsulation Food Industry 267-281.

8. Bishop JRP, Nelson G, Lamb J. 1998. Microencapsulation in yeast cells. J. Microencapsul. 15: 761-773.

9. Normand V, Dardelle G, Bouquerand PE, Nicolas L, Johnston DJ. 2005. Flavor encapsulation in yeasts: limonene used as a model system for characterization of the release mechanism. J. Agric. Food Chem. 53: 7532-7543.

10. Chow CK, Palecek SP. 2004. Enzyme encapsulation in permeabilized Saccharomyces cerevisiae cells. Biotechnol. Progress 20: 449456.

11. Paramera El, Konteles SJ, Karathanos VT. 2011. Microencapsulation of curcumin in cells of Saccharomyces cerevisiae. Food Chem. 125: 892-902.

12. Dardelle G, Normand V, Steenhoudt M, Bouquerand PE, Chevalier M, Baumgartner P. 2007. Flavour-encapsulation and flavourrelease performances of a commercial yeast-based delivery system. Food Hydrocoll. 21: 953-960.

13. Shi G, Rao L, Yu H, Xiang H, Pen G, Long S, Yang C. 2007. Yeastcell-based microencapsulation of chlorogenic acid as a watersoluble antioxidant. J. Food Eng. 80: 1060-1067.

14. Shi G, Rao L, Yu H, Xiang H, Yang H, Ji R. 2008. Stabilization and encapsulation of photosensitive resveratrol within yeast cell. Int. J. Pharm. 349: 83-93.

15. Baş D, Boyac IH. 2005. Modeling and optimization I: Usability of response surface methodology. J. Food Eng. 78: 836-845.

16. Garai D, Kumar V. 2013. Response surface optimization for xylanase with high volumetric productivity by indigenous alkali tolerant Aspergillus candidus under submerged cultivation. 3 Biotech. 3: 127136.

17. Chen W, Wang WP, Zhang HS, Huang Q. 2012. Optimization of ultrasonic-assisted extraction of water-soluble polysaccharides from Boletus edulis mycelia using response surface methodology. Carbohydr. Polym. 87: 614-619.

18. Pham-Hoang BN, Romero-Guido C, Phan-Thi H, Waché Y. 2013. Encapsulation in a natural, preformed, multi-component and complex capsule: yeast cells. Appl. Microbiol. Biotechnol. 97: 66356645.

19. Sangwai MB, Vavia PR. 2011. Effect of decisive formulation variables on bioencapsulation efficiency and integrity of yeast biocapsules for oral itraconazole delivery. J. Microencapsul. 28: 311322.

20. Da Silveira MG, Golovina EA, Hoekstra FA, Rombouts FM, Abee T. 2003. Membrane fluidity adjustments in ethanol-stressed Oenococcus oeni cells. Appl. Environ. Microbiol. 69: 5826-5832.

21. Patra M, Salonen E, Terama E, Vattulainen I, Faller R, Lee BW. et al. 2006. Under the influence of alcohol: the effect of ethanol and methanol on lipid bilayers. Biophys. J. 90: 1121-1135. 